\title{
Stable isotopic constraints on global soil organic carbon turnover
}

\author{
Chao Wang ${ }^{1}$, Benjamin Z. Houlton ${ }^{2}$, Dongwei Liu ${ }^{1}$, Jianfeng Hou ${ }^{1,3}$, Weixin Cheng ${ }^{1,4}$, and Edith Bai ${ }^{1,5}$ \\ ${ }^{1}$ CAS Key Laboratory of Forest Ecology and Management, Institute of Applied Ecology, Chinese Academy of Sciences, \\ Shenyang, 110164, China \\ ${ }^{2}$ Department of Land, Air and Water Resources, University of California, Davis, CA, 95616, USA \\ ${ }^{3}$ College of Resources and Environment, University of Chinese Academy of Sciences, Beijing, 100049, China \\ ${ }^{4}$ Department of Environmental Studies, University of California, Santa Cruz, 1156 High Street, Santa Cruz, CA, 95064, USA \\ ${ }^{5}$ School of Geographical Sciences, Northeast Normal University, Changchun, 130024, China
}

Correspondence: Edith Bai (baie@iae.ac.cn)

Received: 29 July 2017 - Discussion started: 8 September 2017

Revised: 17 January 2018 - Accepted: 17 January 2018 - Published: 20 February 2018

\begin{abstract}
Carbon dioxide release during soil organic carbon (SOC) turnover is a pivotal component of atmospheric $\mathrm{CO}_{2}$ concentrations and global climate change. However, reliably measuring SOC turnover rates on large spatial and temporal scales remains challenging. Here we use a natural carbon isotope approach, defined as beta $(\beta)$, which was quantified from the $\delta^{13} \mathrm{C}$ of vegetation and soil reported in the literature (176 separate soil profiles), to examine large-scale controls of climate, soil physical properties and nutrients over patterns of SOC turnover across terrestrial biomes worldwide. We report a significant relationship between $\beta$ and calculated soil $\mathrm{C}$ turnover rates $(k)$, which were estimated by dividing soil heterotrophic respiration rates by SOC pools. $\ln (-\beta)$ exhibits a significant linear relationship with mean annual temperature, but a more complex polynomial relationship with mean annual precipitation, implying strong-feedbacks of SOC turnover to climate changes. Soil nitrogen $(\mathrm{N})$ and clay content correlate strongly and positively with $\ln (-\beta)$, revealing the additional influence of nutrients and physical soil properties on SOC decomposition rates. Furthermore, a strong $\left(R^{2}=0.76 ; p<0.001\right)$ linear relationship between $\ln (-\beta)$ and estimates of litter and root decomposition rates suggests similar controls over rates of organic matter decay among the generalized soil $\mathrm{C}$ stocks. Overall, these findings demonstrate the utility of soil $\delta^{13} \mathrm{C}$ for independently benchmarking global models of soil $\mathrm{C}$ turnover and thereby improving predictions of multiple global change influences over terrestrial C-climate feedback.
\end{abstract}

\section{Introduction}

Soil contains a large amount of organic carbon (C) and plays a crucial role in regulating Earth's $\mathrm{C}$ cycle and climate system (Schmidt et al., 2011; Reichstein et al., 2013). Approximately $1500 \mathrm{Gt}$ of soil organic carbon (SOC) is stored in the upper meter of global mineral soil (Scharlemann et al., 2014), which is equivalent to $\sim 160$-years worth of current fossil fuel $\mathrm{CO}_{2}$ emissions. However, disagreement exists over the residence time of this vulnerable $\mathrm{C}$ stock and its relationship to factors of ongoing change, particularly climate changes and widespread nitrogen pollution (Reay et al., 2008; Reichstein et al., 2013). Biogeochemical models rely heavily on turnover rates of discrete SOC pools (active, intermediate, and recalcitrant) derived from lab incubation studies (Davidson and Janssens, 2006; Xu et al., 2016). However, in practice SOC pools fall along a continuum of characteristic turnover times from days to centuries (Schmidt et al., 2011; Lehmann and Kleber, 2015), at a given ecosystem site. Furthermore, lab-derived estimates of SOC turnover disrupt the sensitive balance between plant-soil-microbe interactions in ecosystems, adding to questions of the reliability of such techniques when applied to real-world conditions.

The rate of SOC turnover is an important parameter for process-based ecosystem models (Davidson and Janssens, 2006; Schimel et al., 1994), and those used to forecast the global carbon cycle and climate system in the future (Friedlingstein et al., 2006). Global biogeochemical models often use climatic factors such as precipitation and temperature to predict SOC turnover rates (Schimel et al., 1994; 
Nishina et al., 2014). While several studies reported positive relationships between temperature and SOC turnover (Chen et al., 2013; Trumbore et al., 1996; Bird et al., 1996; Trumbore, 1993; Carvalhais et al., 2014), others have called the generality of such relationships into question (Giardina and Ryan, 2000). This discrepancy could be due to interactions among factors which are difficult to separate in the field, for example soil temperature, soil moisture and nutrient controls over SOC decomposition (Davidson and Janssens, 2006). Nitrogen $(\mathrm{N})$ in particular can affect SOC decomposition by changing microbial community structure, microbial activity or both (Curiel et al., 2007). Incorporation of factors unrelated to climate is crucial for improving model performance and predicting the feedback-response of the terrestrial carbon cycle to climate change (Nishina et al., 2014).

In addition, questions remain regarding whether the turnover of different $\mathrm{C}$ stocks behave fundamentally similarly. For example, climate is considered to be a "master regulator" of leaf litter (Zhang et al., 2008), root (Gill and Jackson, 2000; Silver and Miya, 2001) and soil organic C pools (Davidson and Janssens, 2006). However, recent findings have pointed out that soil microbial community composition may play a more important role in litter decomposition rates than climate or litter quality (Bradford et al., 2016; Keiser and Bradford, 2017). Due to the different microbial communities among leaves, roots and soils, and different chemical composition of such pools, rates of $\mathrm{C}$ turnover have the potential to vary widely across generalized classes of $\mathrm{C}$ stocks.

Stable carbon isotope composition $\left(\delta^{13} \mathrm{C}\right)$ provides relatively non-disruptive insights into the turnover of SOC (Garten et al., 2000; Accoe et al., 2002; Powers and Schlesinger, 2002; Bird et al., 1996). For sites with reasonably stable vegetation stocks, measures of vertical soilprofile $\delta{ }^{13} \mathrm{C}$ can provide constraints on SOC turnover rates in ecosystems (Acton et al., 2013; Garten et al., 2000; Wynn et al., 2006). Soil $\delta^{13} \mathrm{C}$ generally increases from shallow to deep mineral soils in relatively well-drained systems, concomitant with decreasing SOC concentrations (Fig. S1 in the Supplement). The vertical distribution of the $\delta^{13} \mathrm{C}$ reflects microbial preferences for ${ }^{12} \mathrm{C}$ vs. ${ }^{13} \mathrm{C}$ in decomposing substrates (Garten et al., 2000), which in turn increases the ${ }^{13} \mathrm{C} /{ }^{12} \mathrm{C}$ of residual organic $\mathrm{C}$ fractions with a kinetic isotope effect defined by $\varepsilon$ (Fig. S1). Therefore, SOC $\delta^{13} \mathrm{C}$ tends to increase with depth along vertical soil profiles until it reaches a maximum value at which point a steady state is achieved (Kohl et al., 2015; Accoe et al., 2002; Brunn et al., 2014, 2016; Garten et al., 2000; Wynn et al., 2006). These trends result in a negative linear relationship between the log-transformed SOC concentration and soil $\delta^{13} \mathrm{C}$ (Acton et al., 2013; Garten et al., 2000; Garten and Hanson, 2006; Powers and Schlesinger, 2002). The slope of the linear regression between soil $\delta^{13} \mathrm{C}$ and the log-transformed SOC concentration is defined as beta $(\beta)$, which has been proposed as a proxy for SOC turnover rate at a select number of sites (Acton et al., 2013; Garten et al., 2000; Powers and Schlesinger, 2002). $\beta$ has also been assessed in set of regional scale analyses (Acton et al., 2013; Brunn et al., 2014). However, whether $\beta$ values can be used to constrain rates and controls on SOC turnover is yet to be explored at the global scale. Furthermore, the Suess effect (the atmospheric isotopically depleted fossil fuel $\mathrm{CO}_{2}$ lowering atmospheric $\delta^{13} \mathrm{C}-\mathrm{CO}_{2}$ ) (Boström et al., 2007; Wynn et al., 2006) and the mixing of different $\mathrm{C}$ sources (Acton et al., 2013; Diochon and Kellman, 2008; Wynn, 2007) may also influence the profile of soil $\delta^{13} \mathrm{C}$ with depth. Identifying the relative influence of different factors in vertical profiles of soil $\delta^{13} \mathrm{C}$ is essential to applying this proxy to patterns of SOM turnover.

Here we examine the efficacy of $\beta$ as a proxy for SOC turnover rates by synthesizing soil profile data from sites around the world (Fig. 1). To understand the overall utility of $\mathrm{C}$ isotope composition for constraining SOC turnover rates, we explore the relationship between $\beta$, modeled SOC decomposition constant $k$ and environmental factors, in particular climate, soil clay content and nutrient availability. We also compare the variation of $\beta$ with that of root and litter turnover rates across latitude (thermal) gradient to examine whether and how the decomposition of generalized $\mathrm{C}$ pools varies as a function of likely controls.

\section{Materials and methods}

\subsection{Data compilation}

Using the key words of "carbon isotope \& vertical profile", " $\delta{ }^{13} \mathrm{C} \&$ soil depth profile", or "soil carbon turnover \& stable isotope" on the Web of Science source, we assembled a total of 149 soil profiles from 51 journal papers (Fig. 1; A list of the literature sources is given in Table S1 in the Supplement). Only soil profiles under pure $C_{3}$ vegetation without significant human disturbance were selected. For each profile, we collected the carbon isotope $\left(\delta^{13} \mathrm{C}\right)$, SOC and $\mathrm{N}$ concentration of leaf-litter, and mineral soil layers at different depths if the data is available, and more than four $\delta^{13} \mathrm{C}$ values should be provided within the top $1 \mathrm{~m}$. Where data were not available in tables, Data Thief software (http://www.datathief.org/) was used to acquire values from figures. We also noted the experiment location (latitude and longitude), biome type, mean annual precipitation (MAP), and mean annual temperature (MAT) for each soil profile. In cases where climate variables were not reported (15 soil profiles out of 149), we used the WorldClim data (http://www.worldclim.com/), which have average monthly temperature and precipitation from 1970 to 2000 with a resolution of $\sim 1 \mathrm{~km}^{2}$ on a global scale, to reconstruct climate values based on latitude and longitude coordinates in ArcGIS version 10.0 using Spatial Analysis tool (ESRI, Redlands, CA). The extracted model data may not precisely match the actual climate data of these 15 soil profiles. However, be- 


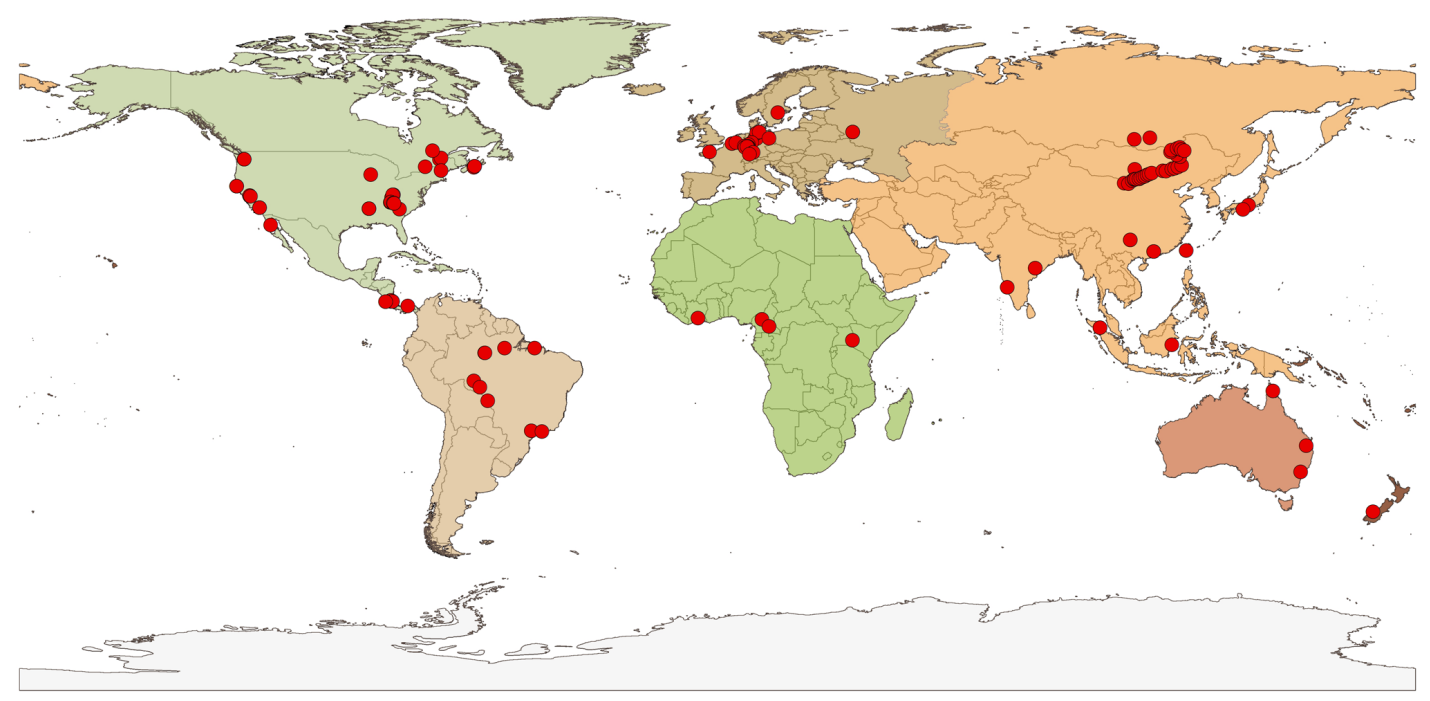

Figure 1. Locations of the 176 soil profiles used to calculate $\beta$ values in this study.

cause the model has been widely tested and accepted (Harbert and Nixon, 2015) and the resolution is high (Hijmans et al., 2005), any deviation should be relatively small.

In addition, a previously reported arid and semi-arid grassland transect along $3000 \mathrm{~km}$ with 27 sampling locations was added into the dataset (Wang et al., 2017), which results in a total of 176 soil profiles in the final dataset. These sampling sites are dominated by $\mathrm{C}_{3}$ plants and cover approximately $16^{\circ}$ longitude ranging from $104^{\circ} 52^{\prime}$ to $120^{\circ} 21^{\prime} \mathrm{E}$ and $10^{\circ}$ latitude ranging from $40^{\circ} 41^{\prime}$ to $50^{\circ} 03^{\prime} \mathrm{N}$. The MAP ranges from 90 to $420 \mathrm{~mm}$ and MAT ranges from -2 to $+7^{\circ} \mathrm{C}$. At each location, five $1 \mathrm{~m} \times 1 \mathrm{~m}$ sub-plots (or one $5 \mathrm{~m} \times 5 \mathrm{~m}$ sub-plot in areas with shrub as the dominating plants) were setup within a $50 \mathrm{~m} \times 50 \mathrm{~m}$ plot. Twenty soil cores $(0-100 \mathrm{~cm})$ in each $1 \mathrm{~m} \times 1 \mathrm{~m}$ sub-plot were collected and divided into $0-10,10-20,20-40,40-60$ and $60-100 \mathrm{~cm}$ depth segments and bulked to form one composite sample for each segment per sub-plot. Leaf samples of five dominating genera (Stipa, Leymus, Caragana, Reaumuria and $\mathrm{Ni}$ traria) were sampled for carbon isotope analysis if these genera were present in the sub-plots.

In a laboratory, leaf samples were washed with deionized water to remove dust particles and then dried at $65^{\circ} \mathrm{C}$ for $48 \mathrm{~h}$. Both soil and leaf samples were ground in a ball mill and stored in a plastic bag. Soil carbonate was removed from soil samples using $0.5 \mathrm{M} \mathrm{HCl}$. Organic carbon concentration and isotope composition of soil and leaf were carried out at the Stable Isotope Faculty of University of California, Davis.

\subsection{Beta calculation}

A negative linear regression between the $\log _{10}$-transformed SOC concentration and $\delta^{13} \mathrm{C}$ for each soil depth profile was conducted (Fig. S1). The slope of this linear regression is

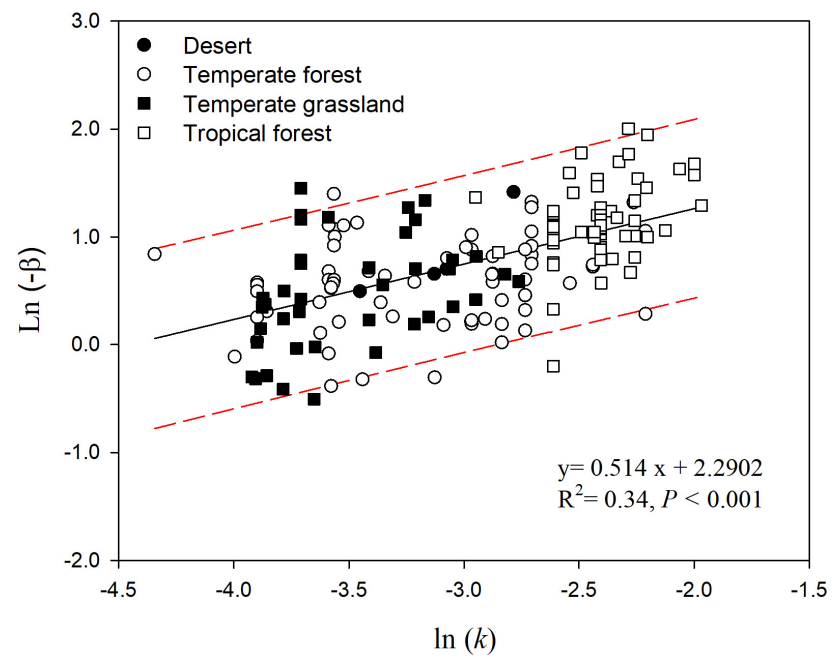

Figure 2. Link between $\beta$ value and modeled soil carbon turnover rate $(k)$, which was estimated as the ratio between soil heterotrophic respiration and soil carbon stocks. Solid line is regression line and dashed lines denote $95 \%$ prediction interval.

defined as beta ( $\beta$ ) value (Acton et al., 2013; Garten et al., 2000; Powers and Schlesinger, 2002).

\subsection{Soil decomposition rate constant $(k)$}

In order to calculate the SOM decomposition rate constant, we assumed a steady state between organic matter inputs to the soil and decomposition rates. We acknowledge that this assumption is not valid in most disturbed environments, including agricultural systems, but it provides a reasonable approximation in natural ecosystems, where SOC turnover does not show significant deviations even on centennial or mil- 


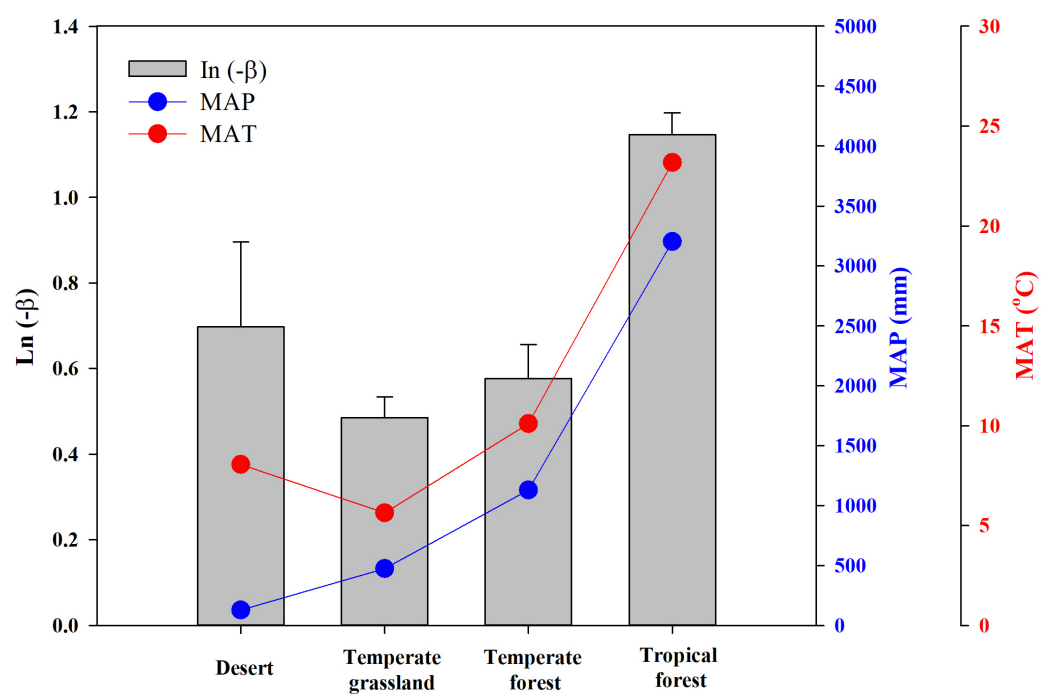

Figure 3. Variations of mean $\beta$ with biome types. Blue and red points present mean annual precipitation (MAP) and mean annual temperature (MAT) for each biome, respectively.

lennial time-scales. The carbon decomposition rate constant $(k)$ was estimated as the ratio between soil heterotrophic respiration $\left(R_{\mathrm{H}}\right)$ and soil organic carbon stock (SOC) (Sanderman et al., 2003): $k=R_{\mathrm{H}}$ /SOC. The SOC stock for each soil profile was extracted from a global soil organic carbon map (within $1 \mathrm{~m}$ depth), created by IGBP-DIS (1998) with a resolution of 0.5 by $0.5^{\circ}$; the mean annual soil total respiration $\left(R_{\mathrm{S}}\right)$ was extracted from a long-term dataset with a resolution of 0.5 by $0.5^{\circ}$ (Raich et al., 2002). We entered the two datasets and the coordinate of soil profiles in ArcGIS (version 10.0, ESRI, Redlands, CA) to extract SOC stock and respiration rates for each profile using the spatial analysis tool. Then we used the linear relationship between soil respiration $\left(R_{\mathrm{S}}\right)$ and $R_{\mathrm{H}}$ to calculate $R_{\mathrm{H}}$ (Bond-Lamberty et al., 2004): $\ln \left(R_{\mathrm{H}}\right)=1.22+0.73 \times \ln \left(R_{\mathrm{S}}\right)$.

\subsection{Data analysis}

Negative $\beta$ value and decomposition rate constant $k$ were $\log$-transformed to perform statistical tests. Larger $\ln (-\beta)$ translated to faster SOC decomposition rates (Acton et al., 2013; Powers and Schlesinger, 2002). Soil $\ln (-\beta)$ was analyzed and summarized across different biome types. Soil $\ln (-\beta)$ was also compared with litter and root decomposition rate along latitude at the global scale. Two-variable regression analysis was first performed to explore the relationship between $\ln (-\beta)$ and $\ln (k)$, or $\ln (-\beta)$ and climate variables (MAP and MAT) as well as soil edaphic factors ( $\mathrm{N}$ and clay content). Multiple regression analysis was then used to examine the relationship between $\ln (-\beta)$ and these variables (MAP, MAT, soil N and clay content). Akaike information criterion (AIC) was used to estimate the quality of model when increasing the number of parameters.

\section{Results}

\subsection{Worldwide patterns of $\beta$}

A total of 176 soil profiles from all continents excluding Antarctica were included in our compiled dataset (Fig. 1). Carbon isotope composition $\left(\delta^{13} \mathrm{C}\right)$ increased with soil depth in the majority of examined profiles and was strongly correlated with the logarithm of SOC (Table S1). $\ln (-\beta)$ was significantly positively related with site-based estimates of the soil C decomposition constant, $\ln (k)$ with $R^{2}=0.34$ (Fig. 2).

The values for $\ln (-\beta)$ ranged from -0.50 to 2.20 across sites (non-transformed $\beta$ values ranged from -0.60 to -7.41 , Table S1). Highest mean $\ln (-\beta)$ was observed in tropical forests (Fig. 3), followed by deserts, temperate forests, and temperate grasslands, with a mean value of $1.15,0.70,0.58$ and 0.49 , respectively. MAP among these four biomes increased from desert $<$ temperate grassland $<$ temperate forest $<$ tropical forest and MAT increased from temperate grassland $<$ desert $<$ temperate forest $<$ tropical forest (Fig. 3).

Along the latitude gradient, $\ln (-\beta)$ decreased from the equator to the poles, but was higher at $20-30^{\circ} \mathrm{N}$ compared to the $10-20^{\circ} \mathrm{N}$ latitudinal band (Fig. $4 \mathrm{a}$ ). The mean decomposition rate of leaf-litter and root $\mathrm{C}$ displayed similar latitudinal patterns $\left(R^{2}=0.76 ; p<0.001\right.$, Fig. $\left.4 \mathrm{~b}\right)$.

\subsection{Controls on $\beta$ across ecosystems}

The $\ln (-\beta)$ and MAT displayed a strong, positive relationship across the global dataset $\left(R^{2}=0.43 ; P<0.001\right.$; Fig. 5a). $\operatorname{Ln}(-\beta)$ did not show a simple linear correlation with MAP, but instead showed a polynomial relationship with a tipping point at $\mathrm{MAP}=3000 \mathrm{~mm}$ (Fig. 5b). When 
Table 1. Multiple regressions between $\ln (-\beta)$ and climate and other edaphic factors at global scale.

\begin{tabular}{lrrr}
\hline Variables & $R^{2}$ & $n$ & AIC \\
\hline $\ln (-\beta)=0.046 \mathrm{MAT}-0.058 \mathrm{MAP}+0.225$ & $0.43^{*}$ & 176 & 167.30 \\
$\ln (-\beta)=0.053 \mathrm{MAT}-0.137 \mathrm{MAP}+0.384 N+0.150$ & $0.55^{*}$ & 104 & 64.71 \\
$\ln (-\beta)=0.046 \mathrm{MAT}-0.222 \mathrm{MAP}+0.849 N+0.006$ Clay +0.069 & $0.66^{*}$ & 70 & 28.95 \\
\hline
\end{tabular}

MAT: Mean Annual Temperature $\left({ }^{\circ}\right)$; MAP: Mean Annual Precipitation $(\mathrm{m}) ; N$ : Soil nitrogen concentration $(\%)$ in topsoil. Clay: Soil clay concentration (\%) in topsoil. $n$ is the number of data, and $R^{2}$ is the coefficient of determination for the regression line. AIC: Akaike information criterion. * represents significant at $p$ less than 0.001 .

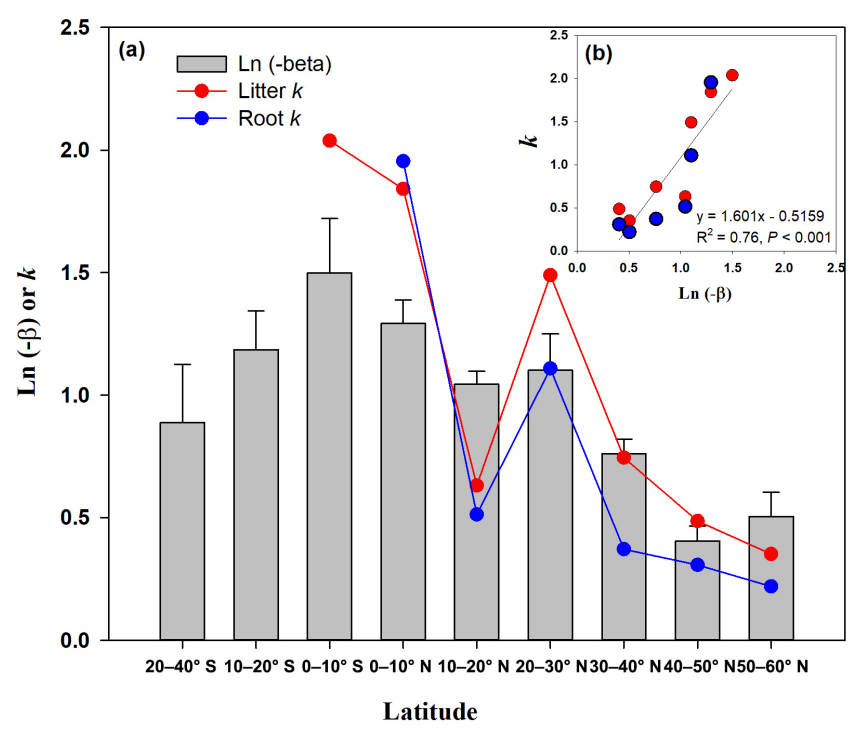

Figure 4. Variation of mean $\ln (-\beta)$ value across latitude (bar chart), litter decomposition rate $k$ ( $\mathrm{yr}^{-1}$, red dots; Zhang et al., 2008) and root decomposition rate $k\left(\mathrm{yr}^{-1}\right.$, blue dots; Silver and Miya, 2001) at the global scale. The inner panel is the regression between soil $\ln (-\beta)$ value and litter and root decomposition rate $k$.

MAP was less than $3000 \mathrm{~mm}, \ln (-\beta)$ was positively correlated with $\operatorname{MAP}\left(R^{2}=0.23, P<0.001\right) ; \ln (-\beta)$ decreased with the increasing of MAP in areas receiving $>3000 \mathrm{~mm}$ of MAP. A quadratic equation provided the best fit to the relationship between $\ln (-\beta)$ and MAP for all sites $\left(R^{2}=0.24\right.$, $P<0.001$; Fig. 5 b). Soil N explained $20 \%$ of the variations in $\ln (-\beta)(P<0.001$; Fig. $5 \mathrm{c})$. Moreover, a quadratic equation best described the relationship between soil clay and $\ln (-\beta)$, with $R^{2}=0.49(P<0.001$; Fig. 5d). AIC analysis showed that the full-factors model (i.e., MAT, MAP, soil N and clay) accounted for more of the variation in $\ln (-\beta)$ than any other regression model in the global data set (Table 1).

\section{Discussion}

Our global data synthesis reveals significant relationships between $\ln (-\beta)$ and the turnover of soil, litter and root $\mathrm{C}$ pools at geographically broad scales (Figs. 2 and 4). These findings build on site-based observations and regional assess- ments (Accoe et al., 2002; Garten et al., 2000; Powers and Schlesinger, 2002; Brunn et al., 2014, 2016), and suggest that $\mathrm{C}$ isotope composition is a useful proxy for understanding generalized patterns of SOC turnover and the underlying controls over soil $\mathrm{C}$ metabolism. That our results hold across all major soil C pools implies that SOC, root and litter turnover share common controls, in particular those related to climate and soil nitrogen contents. These findings suggest that decomposition of belowground and aboveground soil C may have similar responses to global climate change, such as global warming and increasing atmospheric $\mathrm{N}$ deposition. Furthermore, our results highlight the potential of incorporating natural stable $\mathrm{C}$ isotopes in global biogeochemical and Earth system models to constrain soil and litter decomposition rates that are vital to climate change forecasts.

Within the terrestrial biosphere, our findings point to the highest mean $\ln (-\beta)$ in tropical forest ecosystems, indicating a high SOC decomposition rate in these regions, which is consistent with previous studies (Carvalhais et al., 2014). At the other extreme, our analysis suggests that slowest mean rates of SOC decomposition occur in temperate grassland (Fig. 3), consistent with results from previous simulation modeling (Carvalhais et al., 2014; Schimel et al., 1994). Relatively slow decomposition rates have been observed for plant litter decay in arid grassland sites (Zhang et al., 2008), and largely reflects strong moisture controls on decomposition. In addition, microbial biomass and microbial activities are much lower in arid/semi-arid vs. mesic or humid sites (Fierer et al., 2009), thus leading to low rates of SOC and litter decomposition.

\subsection{Climate and nutrient dependences of $\beta$}

The differences of $\beta$ value among different biomes reflect several controlling variables especially mean annual temperature, mean annual precipitation, soil $\mathrm{N}$ contents, and clay content. Of particular importance is temperature-driven controls over $\beta$, in which MAT explains $43 \%$ of the variation of $\ln (-\beta)$ in our global data compilation (Table 1; Fig. 5a). A recent meta-analysis, which included 24 soil profiles across a range of cool temperate to tropical forest sites, reported similarly strong temperature-dependencies of $\beta$ (Acton et al., 2013). Our findings broaden this perspective to a global range of terrestrial biomes and climates, and indicate that, 

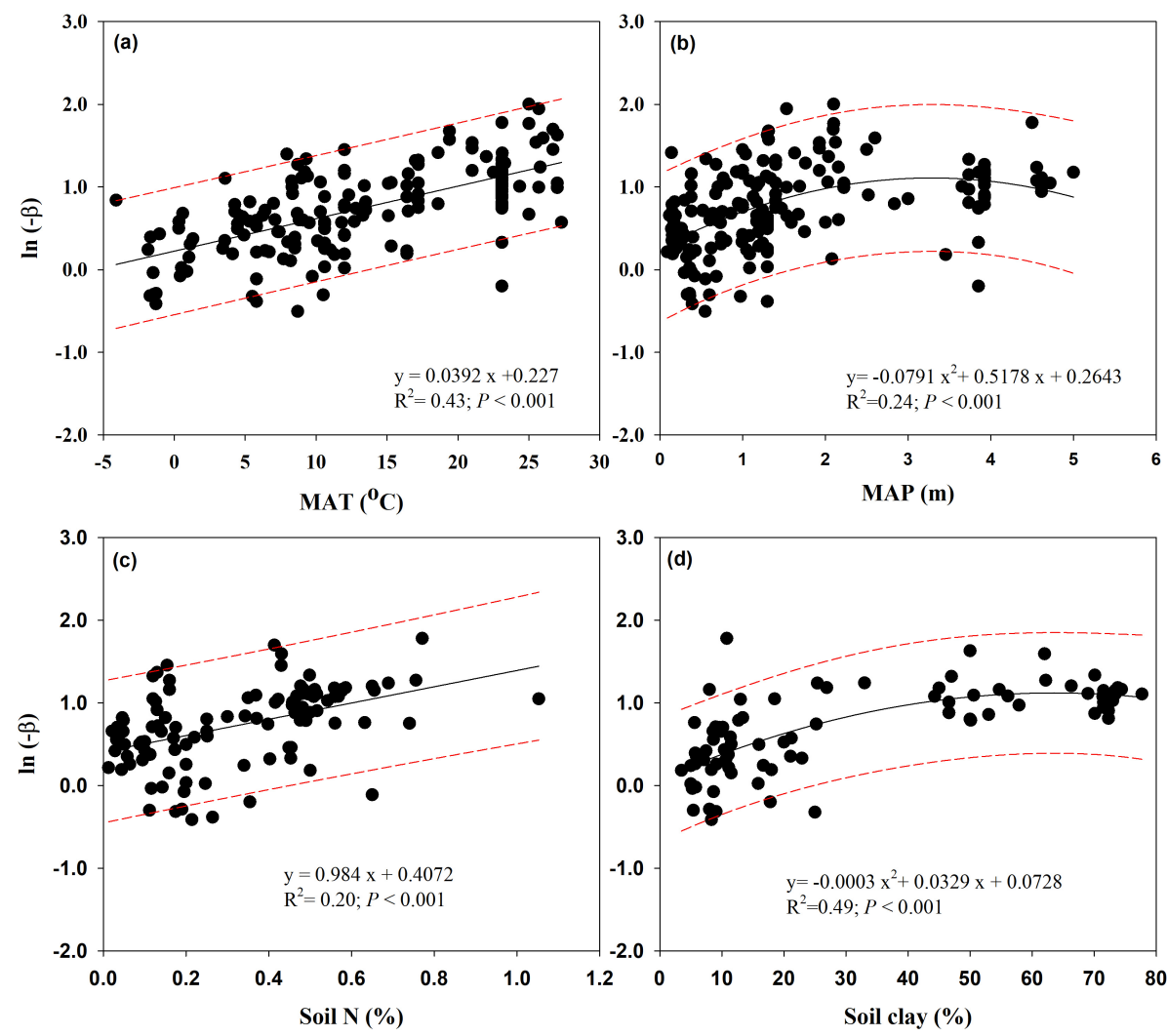

Figure 5. Beta varied with climatic and edaphic factors. Relationships between $\ln (-\beta)$ and MAT (a), MAP (b), soil N (c), and clay concentration (d) for global dataset. Solid line is regression line and dashed lines denote $95 \%$ prediction interval.

with increasing MAT, SOC turnover is substantially accelerated. This result agrees with previous studies which have identified temperature as the strongest regulator of soil $\mathrm{C}$ decomposition among all known controls (Carvalhais et al., 2014; Schimel et al., 1994), and is consistent with global Cclimate feedback models, which project accelerated rates of $\mathrm{CO}_{2}$ efflux from the land biosphere with climate warming (Ciais et al., 2014).

Our study also points to significant relationships between $\beta$ and precipitation-climates, which are more complex than those observed for MAT. Rather, we find an inflection point in $\beta$ in our global data set at MAP $\sim 3000 \mathrm{~mm}$ (Fig. 5b). This relationship reveals negative effects of moisture on change of soil $\delta^{13} \mathrm{C}$ in very wet climates. A cross-system compilation of the smaller though more dynamic litter pool shows a similar pattern of decreasing decay rates in regions with MAP $>3000 \mathrm{~mm}$ compared to drier sites (Zhang et al., 2008). In addition, Schuur (2001) showed that leaf and root decomposition rates declined significantly with increasing precipitation along a highly constrained rainfall sequence in Hawaiian forest sequence (from $2020 \mathrm{~mm}<\mathrm{MAP}<5050 \mathrm{~mm}$ ). This resulted in slower rates of nutrient mineralization and declines in net primary production (NPP) at the wettest sites. The consistency between our study and past work suggests that precipitation affects the decomposition of SOC and litter in similar ways, slowing decomposition rates when MAP is very high and anaerobic conditions dominate (i.e. MAP > 3000 mm; Schuur, 2001).

In addition to climate, nutrients influence the magnitude of $\ln (-\beta)$ in our compilation, with SOC turnover rates generally increasing with soil $\mathrm{N}$ concentrations across ecosystem sites (Table 1, Fig. 5c). Although soil $\mathrm{N}$ has been suggested as an important control over SOC decomposition in previous work (Schimel et al., 1994), our study is one of the few to confirm the existence of such a relationship at the global scale. Positive correlations between litter decomposition rates and litter $\mathrm{N}$ contents during the early stages of decay have been reported previously (Berg, 2000). Past work has also suggested that high $\mathrm{N}$ availability enhances soil degrading enzyme activities (Fioretto et al., 2007).

Finally, our results suggest that physical soil factors, particularly soil clay content, plays a role in $\ln (-\beta)$ and soil organic C turnover (Fig. 5d), consistent with previous expectations (Schimel et al., 1994; Xu et al., 2016). In sites where clay content is $<50 \%$ (i.e., sandy soils), for example $\ln (-\beta)$ increases with the soil clay content. However, when clay content is $>50 \%$ (loamy or clayey soils), no clear relationship between $\ln (-\beta)$ and clay content is observed (Fig. $5 d$ ). The 
change in this relationship could be explained by the higher "preservation capacity" of clayey soils (Vogel et al., 2014).

SOC turnover is an important parameter for process-based models and Earth system models (Schimel et al., 1994; Davidson and Janssens, 2006), and models used to forecast the carbon cycle and climate system into the future (Friedlingstein et al., 2006). Global biogeochemical models commonly use climatic factors as predictors of SOC turnover rates (Carvalhais et al., 2014). In contrast, our results point to factors beyond climate alone, but include soil $\mathrm{N}$ content and soil texture, as factors altering organic $\mathrm{C}$ turnover across the terrestrial biosphere. Taken together for instance, our multiple regression analysis considering all factors (i.e., MAT, MAP, soil $\mathrm{N}$ and clay) explains nearly $70 \%$ of variation of $\ln (-\beta)\left(R^{2}=0.66, P<0.001\right.$; Table 1$)$, suggesting the high dependence of SOC turnover on these factors. We therefore suggest the need for models that include all of these factors when forecasting global $\mathrm{C}$ cycle response to change.

In addition, our findings suggest that the $\mathrm{C}$ isotope composition of the soil can help to improve global $\mathrm{C}$ model performance. A common problem in global $\mathrm{C}$ research is finding consistent and sufficiently integrated metrics against which the performance of different biogeochemical models can be quantitatively analyzed (Tian et al., 2015). The strong relationships we observe between $\beta$ and SOC turnover $(k)$ suggest that this natural-isotope proxy can be used to groundtruth large-scale patterns of model-simulated soil C dynamics. It should be noted that the $k$ values were based on multiple data sources of soil carbon storage and respiration, which might add uncertainty to the regression statistics between $\ln (-\beta)$ and $\ln (k)$.

Future work to collect and analyze $\mathrm{C}$ isotope data in vertical soil profiles, which is a relatively inexpensive process, can further extend the regional coverage of $\beta$ and help benchmark SOC turnover estimates among global model simulations. This is important given the potential for SOC turnover to respond to multiple global changes and produce significant feedbacks on climate at the global scale (Carvalhais et al., 2014; Lehmann and Kleber, 2015). Further, application of our results to ecosystems that are far from steady-state should be approached with caution.

\subsection{Alternative controls over soil $\delta^{13} \mathrm{C}$ with depth}

Several processes have been proposed to explain the widely observed pattern of increasing $\delta^{13} \mathrm{C}$ from shallow to deep soils beyond those related to kinetic isotope fractionation during decomposition. For example, atmospheric $\delta^{13} \mathrm{C}-\mathrm{CO}_{2}$ has been decreasing since the Industrial Revolution owing to the combustion of ${ }^{13} \mathrm{C}$-depleted fossil fuels, which could lead to lower $\delta^{13} \mathrm{C}$ in surface soils vs. deeper horizons (Friedli et al., 1987). However, the magnitude of this effect is small (i.e., 1.4-1.5\%o) compared to the substantial variation of soil $\delta^{13} \mathrm{C}$ along depth profiles $(\sim 3.5 \%$ ) in our dataset. Based on a 100-year-old soil archive (i.e. soil collected before ex- tensive fossil fuel $\mathrm{CO}_{2}$ emissions) and modern samples collected from a common site in the Russian steppe, Torn et al. (2002) demonstrated that $\delta^{13} \mathrm{C}$ profiles of modern and preindustrial soils were similar. Thus, the $\delta^{13} \mathrm{C}$ values of SOM in soil profiles that can be attributed to the changes in the $\delta^{13} \mathrm{C}$ of atmospheric $\mathrm{CO}_{2}$ should be small.

In addition, bioturbation and consequent mixing of $\mathrm{C}$ from different sources has the potential to alter soil $\delta^{13} \mathrm{C}$ profiles (Acton et al., 2013; Ehleringer et al., 2000). The $\delta^{13} \mathrm{C}$ of root material is generally higher than that of above ground biomass, such as leaves (Powers and Schlesinger, 2002), and so the $\delta^{13} \mathrm{C}$ of SOC at the soil surface may be lower than deep soils. Because microbes, invertebrates, and other soil fauna are typically enriched in $\delta^{13} \mathrm{C}$ compared to source-substrates, biological migration and physical mixing of soils may alter relationships between soil $\mathrm{C}$ concentrations and $\delta^{13} \mathrm{C}$ (Wynn et al., 2006). Kohl et al. (2015) suggested that increased proportions of soil bacteria $\left({ }^{13} \mathrm{C}\right.$ enriched) relative to fungi $\left({ }^{13} \mathrm{C}\right.$ depleted) biomass might also contribute to increasing $\delta^{13} \mathrm{C}$ with depth. However, the process-based modeling predicts the opposite pattern (Acton et al., 2013).

Moreover, in extremely wet sites it is likely that leaching of dissolved organic carbon (DOC) from soils to streams affects the relationship between decomposition and isotope effect expression (Powers and Schlesinger, 2002). Previous studies have shown that DOC increases with increasing soil depth (Kaiser et al., 2001). As DOC is generally ${ }^{13} \mathrm{C}$ enriched (Kaiser et al., 2001), increasing DOC leaching into very wet sites would be expected to induce a larger change in soil $\delta^{13} \mathrm{C}$ with depth, and hence, increasing $\ln (-\beta)$.

\section{Conclusion}

Our analysis provides a globally integrative tool for understanding variations of SOC turnover rate, which can be applied spatially based on estimates of factors such as climate and soil properties. Compared with other methods, utilization of $\mathrm{C}$ isotope composition ratios in soil profile provides an independent approach that does not rely on disruption of plant-soil-microbe interactions. It has the added benefit of integrating over longer time scales (decade to centuries), and thus provides a common measurement for model-based benchmarking and calibration schemes.

Data availability. The data used in this study can be found in the Supplement.

The Supplement related to this article is available online at https://doi.org/10.5194/bg-15-987-2018-supplement. 
Author contributions. $\mathrm{CW}$ and $\mathrm{EB}$ conceived and wrote the paper with contributions from BZH. CW, WC, DL and JH conducted the field and laboratory works. CW, EB and DL compiled data from peer-reviewed publications and conducted the modeling. All coauthors interpreted the results.

Competing interests. The authors declare that they have no conflict of interest.

Acknowledgements. We are extremely grateful to all authors of the studies we used for the present work and whose publication references are presented in the Supplement. We deeply thank Jérôme Balesdent and one anonymous reviewer and the editor who handled this manuscript, for their useful comments. This work was financially supported by the National Basic Research Program of China (973 program; 2014CB954400), the National Natural Science Foundation of China (41601255, 31522010 and 31600358), the Key Research Program of Frontier Sciences, CAS (QYZDB-SSW-DQC006), and the Youth Innovation Promotion Association CAS to Chao Wang.

Edited by: Jens-Arne Subke

Reviewed by: Jérôme Balesdent and one anonymous referee

\section{References}

Accoe, F., Boeckx, P., Cleemput, O. V., Hofman, G., Zhang, Y., and Guanxiong, C.: Evolution of the $\delta^{13} \mathrm{C}$ signature related to total carbon contents and carbon decomposition rate constants in a soil profile under grassland, Rapid Commun. Mass Sp., 16, 2184-2189, 2002.

Acton, P., Fox, J., Campbell, E., Rowe, H., and Wilkinson, M.: Carbon isotopes for estimating soil decomposition and physical mixing in well-drained forest soils, J. Geophys. Res.-Biogeo., 118, 1532-1545, 2013.

Berg, B.: Litter decomposition and organic matter turnover in northern forest soils, Forest Ecol. Manag., 133, 13-22, 2000.

Bird, M. I., Chivas, A. R., and Head, J.: A latitudinal gradient in carbon turnover times in forest soils, Nature, 381, 143-146, 1996.

Bond-Lamberty, B., Wang, C., and Gower, S. T.: A global relationship between the heterotrophic and autotrophic components of soil respiration?, Glob. Change Biol., 10, 1756-1766, 2004.

Boström, B., Comstedt, D., and Ekblad, A.: Isotope fractionation and ${ }^{13} \mathrm{C}$ enrichment in soil profiles during the decomposition of soil organic matter, Oecologia, 153, 89-98, 2007.

Bradford, M. A., Berg, B., Maynard, D. S., Wieder, W. R., Wood, S. A., and Cornwell, W.: Understanding the dominant controls on litter decomposition, J. Ecol., 104, 229-238, 2016.

Brunn, M., Spielvogel, S., Sauer, T., and Oelmann, Y.: Temperature and precipitation effects on $\delta^{13} \mathrm{C}$ depth profiles in SOM under temperate beech forests, Geoderma, 235-236, 146-153, 2014.

Brunn, M., Condron, L., Wells, A., Spielvogel, S., and Oelmann, Y.: Vertical distribution of carbon and nitrogen stable isotope ratios in topsoils across a temperate rainforest dune chronosequence in New Zealand, Biogeochemistry, 129, 37-51, 2016.
Carvalhais, N., Forkel, M., Khomik, M., Bellarby, J., Jung, M., Migliavacca, M., u, M., Saatchi, S., Santoro, M., Thurner, M., Weber, U., Ahrens, B., Beer, C., Cescatti, A., Randerson, J. T., and Reichstein, M.: Global covariation of carbon turnover times with climate in terrestrial ecosystems, Nature, 514, 213-217, 2014.

Chen, S., Huang, Y., Zou, J., and Shi, Y.: Mean residence time of global topsoil organic carbon depends on temperature, precipitation and soil nitrogen, Global Planet. Change, 100, 99-108, 2013.

Ciais, P., Sabine, C., Bala, G., Bopp, L., Brovkin, V., Canadell, J., Chhabra, A., DeFries, R., Galloway, J., and Heimann, M.: Carbon and other biogeochemical cycles, in: Climate Change 2013: The Physical Science Basis. Contribution of Working Group I to the Fifth Assessment Report of the Intergovernmental Panel on Climate Change, Cambridge University Press, 465-570, 2014.

Curiel, Y. J., Baldocchi, D. D., Gershenson, A., Goldstein, A., Misson, L., and Wong, S.: Microbial soil respiration and its dependency on carbon inputs, soil temperature and moisture, Glob. Change Biol., 13, 2018-2035, 2007.

Davidson, E. A. and Janssens, I. A.: Temperature sensitivity of soil carbon decomposition and feedbacks to climate change, Nature, 440, 165-173, 2006.

Diochon, A. and Kellman, L.: Natural abundance measurements of ${ }^{13} \mathrm{C}$ indicate increased deep soil carbon mineralization after forest disturbance, Geophys. Res. Lett., 35, L14402, https://doi.org/10.1029/2008GL034795, 2008.

Ehleringer, J. R., Buchmann, N., and Flanagan, L. B.: Carbon isotope ratios in belowground carbon cycle processes, Ecol. Appl., 10, 412-422, 2000.

Fierer, N., Strickland, M. S., Liptzin, D., Bradford, M. A., and Cleveland, C. C.: Global patterns in belowground communities, Ecol. Lett., 12, 1238-1249, 2009.

Fioretto, A., Papa, S., Pellegrino, A., and Fuggi, A.: Decomposition dynamics of Myrtus communis and Quercus ilex leaf litter: Mass loss, microbial activity and quality change, Appl. Soil Ecol., 36, 32-40, 2007.

Friedli, H., Siegenthaler, U., Rauber, D., and Oeschger, H.: Measurements of concentration, ${ }^{13} \mathrm{C} /{ }^{12} \mathrm{C}$ and ${ }^{18} \mathrm{O} /{ }^{16} \mathrm{O}$ ratios of tropospheric carbon dioxide over Switzerland, Tellus B, 39, 8088, 1987.

Friedlingstein, P., Cox, P., Betts, R., Bopp, L., Von Bloh, W., Brovkin, V., Cadule, P., Doney, S., Eby, M., and Fung, I.: Climate-carbon cycle feedback analysis: Results from the C4MIP model intercomparison, J. Climate, 19, 3337-3353, 2006.

Garten, C. T. and Hanson, P. J.: Measured forest soil C stocks and estimated turnover times along an elevation gradient, Geoderma, 136, 342-352, 2006.

Garten, C. T., Cooper, L. W., Post III, W., and Hanson, P. J.: Climate controls on forest soil $\mathrm{C}$ isotope ratios in the southern Appalachian Mountains, Ecology, 81, 1108-1119, 2000.

Giardina, C. P. and Ryan, M. G.: Evidence that decomposition rates of organic carbon in mineral soil do not vary with temperature, Nature, 404, 858-861, 2000.

Gill, R. A. and Jackson, R. B.: Global patterns of root turnover for terrestrial ecosystems, New Phytol., 147, 13-31, 2000.

Harbert, R. S. and Nixon, K. C.: Climate reconstruction analysis using coexistence likelihood estimation (CRACLE): A method 
for the estimation of climate using vegetation, Am. J. Bot., 102, 1277-1289, 2015.

Hijmans, R. J., Cameron, S. E., Parra, J. L., Jones, P. G., and Jarvis, A.: Very high resolution interpolated climate surfaces for global land areas, Int. J. Climatol., 25, 1965-1978, 2005.

IGBP-DIS: SoilData (V.0). A program for creating global soilproperty databases, IGBP Global Soils Data Task, France, 1998.

Kaiser, K., Guggenberger, G., and Zech, W.: Isotopic fractionation of dissolved organic carbon in shallow forest soils as affected by sorption, Eur. J. Soil Sci., 52, 585-597, 2001.

Keiser, A. D. and Bradford, M. A.: Climate masks decomposer influence in a cross-site litter decomposition study, Soil Biol. Biochem., 107, 180-187, 2017.

Kohl, L., Laganière, J., Edwards, K. A., Billings, S. A., Morrill, P. L., Van Biesen, G., and Ziegler, S. E.: Distinct fungal and bacterial $\delta^{13} \mathrm{C}$ signatures as potential drivers of increasing $\delta^{13} \mathrm{C}$ of soil organic matter with depth, Biogeochemistry, 124, 13-26, 2015.

Lehmann, J. and Kleber, M.: The contentious nature of soil organic matter, Nature, 528, 60-68, 2015.

Nishina, K., Ito, A., Beerling, D. J., Cadule, P., Ciais, P., Clark, D. B., Falloon, P., Friend, A. D., Kahana, R., Kato, E., Keribin, R., Lucht, W., Lomas, M., Rademacher, T. T., Pavlick, R., Schaphoff, S., Vuichard, N., Warszawaski, L., and Yokohata, T.: Quantifying uncertainties in soil carbon responses to changes in global mean temperature and precipitation, Earth Syst. Dynam., 5, 197-209, https://doi.org/10.5194/esd-5-197-2014, 2014.

Powers, J. S. and Schlesinger, W. H.: Geographic and vertical patterns of stable carbon isotopes in tropical rain forest soils of Costa Rica, Geoderma, 109, 141-160, 2002.

Raich, J. W., Potter, C. S., and Bhagawati, D.: Interannual variability in global soil respiration, 1980-94, Glob. Change Biol., 8, 800-812, 2002.

Reay, D. S., Dentener, F., Smith, P., Grace, J., and Feely, R. A.: Global nitrogen deposition and carbon sinks, Nat. Geosci., 1, 430-437, 2008.

Reichstein, M., Bahn, M., Ciais, P., Frank, D., Mahecha, M. D., Seneviratne, S. I., Zscheischler, J., Beer, C., Buchmann, N., Frank, D. C., Papale, D., Rammig, A., Smith, P., Thonicke, K., van der Velde, M., Vicca, S., Walz, A., and Wattenbach, M.: Climate extremes and the carbon cycle, Nature, 500, 287-295, 2013.

Sanderman, J., Amundson, R. G., and Baldocchi, D. D.: Application of eddy covariance measurements to the temperature dependence of soil organic matter mean residence time, Global Biogeochem. Cy., 17, GB001833, https://doi.org/10.1029/2001GB001833, 2003.

Scharlemann, J. P., Tanner, E. V., Hiederer, R., and Kapos, V.: Global soil carbon: understanding and managing the largest terrestrial carbon pool, Carbon Manag., 5, 81-91, 2014.

Schimel, D. S., Braswell, B., Holland, E. A., McKeown, R., Ojima, D., Painter, T. H., Parton, W. J., and Townsend, A. R.: Climatic, edaphic, and biotic controls over storage and turnover of carbon in soils, Global Biogeochem. Cy., 8, 279-293, 1994.

Schmidt, M. W., Torn, M. S., Abiven, S., Dittmar, T., Guggenberger, G., Janssens, I. A., Kleber, M., Kögel-Knabner, I., Lehmann, J., and Manning, D. A.: Persistence of soil organic matter as an ecosystem property, Nature, 478, 49-56, 2011.
Schuur, E. A.: The effect of water on decomposition dynamics in mesic to wet Hawaiian montane forests, Ecosystems, 4, 259-273, 2001.

Silver, W. and Miya, R.: Global patterns in root decomposition: comparisons of climate and litter quality effects, Oecologia, 129, 407-419, 2001.

Tian, H., Lu, C., Yang, J., Banger, K., Huntzinger, D. N., Schwalm, C. R., Michalak, A. M., Cook, R., Ciais, P., Hayes, D., Huang, M., Ito, A., Jain, A. K., Lei, H., Mao, J., Pan, S., Post, W. M., Peng, S., Poulter, B., Ren, W., Ricciuto, D., Schaefer, K., Shi, X., Tao, B., Wang, W., Wei, Y., Yang, Q., Zhang, B., and Zeng, N.: Global patterns and controls of soil organic carbon dynamics as simulated by multiple terrestrial biosphere models: Current status and future directions, Global Biogeochem. Cy., 29, 775792, 2015.

Torn, M. S., Lapenis, A. G., Timofeev, A., Fischer, M. L., Babikov, B. V., and Harden, J. W.: Organic carbon and carbon isotopes in modern and 100 year old soil archives of the Russian steppe, Glob. Change Biol., 8, 941-953, 2002.

Trumbore, S. E.: Comparison of carbon dynamics in tropical and temperate soils using radiocarbon measurements, Global Biogeochem. Cy., 7, 275-290, 1993.

Trumbore, S. E., Chadwick, O. A., and Amundson, R.: Rapid Exchange Between Soil Carbon and Atmospheric Carbon Dioxide Driven by Temperature Change, Science, 272, 393-396, 1996.

Vogel, C., Mueller, C. W., Höschen, C., Buegger, F., Heister, K., Schulz, S., Schloter, M., and Kögel-Knabner, I.: Submicron structures provide preferential spots for carbon and nitrogen sequestration in soils, Nat. Commun., 5, 2947, https://doi.org/10.1038/ncomms3947, 2014.

Wang, C., Wei, H., Liu, D., Luo, W., Hou, J., Cheng, W., Han, X., and Bai, E.: Depth profiles of soil carbon isotopes along a semiarid grassland transect in northern China, Plant Soil, 417, 43-52, 2017.

Wynn, J. G.: Carbon isotope fractionation during decomposition of organic matter in soils and paleosols: implications for paleoecological interpretations of paleosols, Palaeogeogr. Palaeocl., 251, 437-448, 2007.

Wynn, J. G., Harden, J. W., and Fries, T. L.: Stable carbon isotope depth profiles and soil organic carbon dynamics in the lower Mississippi Basin, Geoderma, 131, 89-109, 2006.

Xu, X., Shi, Z., Li, D., Rey, A., Ruan, H., Craine, J. M., Liang, J., Zhou, J., and Luo, Y.: Soil properties control decomposition of soil organic carbon: Results from data-assimilation analysis, Geoderma, 262, 235-242, 2016.

Zhang, D., Hui, D., Luo, Y., and Zhou, G.: Rates of litter decomposition in terrestrial ecosystems: global patterns and controlling factors, J. Plant Ecol., 1, 85-93, 2008. 